\title{
Atoms Want to Be Free Too! Expanding the Critique of In- tellectual Property to Physical Goods
}

\author{
Johan Söderberg* and Adel Daoud** \\ *Department of Sociology, University of Gothenburg, Gothenburg, Sweden,
johan.soderberg@sts.gu.se
** Department of Sociology, University of Gothenburg, Gothenburg, Sweden,
adeldaoud@gmail.com
}

\begin{abstract}
Atoms are the new bits". That is the latest buzz arising from the Californian trade press. What do we get when this dictum is sampled with the old rallying cry: "Information wants to be free"? We suggest that the predominant, bounded critique of intellectual property is thereby destabilised. Constitutive of that critique was the exceptionality attributed to information goods (bits) vis-a-vis tangible goods (atoms). It was thus intellectual property could be presented as something altogether different from private property. We recognise that this way of framing the issue has had tactical advantages, but contend that it has stood in the way of a deeper understanding of what intellectual property is. When the critique of proprietary software is expanded by an emerging movement for open hardware development, however, the boundary between intellectual property and property as such crumbles. This enables us to renew our critique of the political economy of information.
\end{abstract}

Keywords: New Media Studies, Science and Technology Studies, Economic Sociology, Information, Property, Hackers, Open-Hardware, Hacking

In the science fiction story Printcrime from 2006, Cory Doctorow canvased a future society where the development of $3 \mathrm{D}$ printers has made it possible to copy physical goods in much the same way as digital information can be copied today. Abiding to the tradition of the cyberpunk genre, Doctorow depicted a dystopia where an oppressive state working for a handful of global conglomerates had outlawed the practice of copying physical goods. Subsequently, the protagonist of the story has been found guilty of committing this crime. The story ends when he is released from the prison after having served a ten years sentence. He recognises his folly of having wasted time with printing electronic gadgets and pharmaceuticals. This time, he declares: "I'm going to print more printers. Lots more printers. One for everyone. That's worth going to jail for."

The idea behind the Printcrime story resonates with the ambitions of a group of university researchers and hobbyists who are working on an open source 3D printer. The project was started by Adrian Bowyer at the mechanical engineering department at Bath University in 2005. Over the years it has attracted a large, global following out of which many are participating in the development of the 3D printer. In regards to the present argument, what is of interest is the core idea behind the project, as suggested by its name: "Rep-rap". It is an abbreviation of "self-replicating rapid prototyper". Their goal is to design the 3D printer in such a way that it can print most of its own parts. In addition to copying itself, such a machine would be able to produce a range of useful and trivial goods. Many of the hobbyists expect that the emergence of small-scale home manufacturing, where cheap and user-friendly 3D-printers play a key part, will disrupt established patterns of mass-production, mass-consumption and global distribution networks. The ideas of Cory Doctorow are echoed in the discussion forum of the Rep-rap community. One can find many speculations about what kind of legal repercussions this technology will provoke from the powers-that-be. Partly responding to these concerns, one study has compared existing intellectual property rights in the UK, chiefly patents, copyright, trademarks and bans on passing-off, and concluded that none of these are likely to interfere with home 3D printing (Bradshaw, Bowyer, and Haufe 2010). However, given the speed by which new intellectual property rights are being introduced today, this conclusion might not be much of reassurance. And at least some of the advocates of the Rep-rap project are eager to bring on an expanded conflict over intellectual property. A small token hereof was the launch in 2010 of "The Product Bay" by one of the founders of the (in)famous Swedish filesharing service "the Pirate Bay". The design of the Rep-rap machine and auxiliary development projects are to some extent dictated by the same combative spirit among the hobbyists. A case in point is the efforts channelled into designing user-friendly 3D scanners. With a 3D scanner, new design 
files can be generated (scanned) from existing physical objects. The stated purpose of having such a scanner is to enlarge the capacity to rip, mix and burn physical objects.

We will leave aside the question how the dreams about what the Rep-rap machine will do in the near future diverges from what it actually can do. Certainly, the gap is considerable. Instead, we propose to take this example as a point of departure for reflecting over the political economy of information/communication. Thus we align ourselves with a theoretical school where studies of new media and communication technologies are placed within a larger social whole of production, commodification, power relations, etc. In other words, an approach, which builds on Marx's critique of the political economy and which today, is upheld by a strand of heterodox economists (Mosco 1996, 71-72, 172; Mansell 2004). With a few notable exceptions, such a line of reasoning has been absent from the predominant critique against the intellectual property regime. In the first half of the article, we will suggest why that might be. In brief, the predominant critique is made up of an amalgam between, one the one hand, the limited self-understanding of free software/open source advocates, and, on the other hand, the limited theoretical presumptions of the classical and neoclassical economic paradigm. As a direct result hereof, intellectual property is portrayed as something radically different from private property.

In the section, which follows, we will investigate how this separation is anchored in a more fundamental, not to say "ontological", assertion about the otherness of the virtual realm. Its corollary assumption is the exceptionality attributed to informational resources vis-à-vis physical goods. Dan Schiller has named this idea the "information exceptionalism" hypothesis. We will argue that this hypothesis has been constitutive for framing the predominant critique of the intellectual property regime. Hackers, geeks, self-acclaimed pirates, and quite a few legal scholars too, are engaged in "boundary work". In other words, they are setting up a boundary between information and physical goods in order to exclude private property and free markets from their critique of intellectual property. This approach has advantages when trying to sway policy makers or seeking to unite the many, warring fractions within the hacker scene behind a common stand against intellectual property. Unfortunately, tactical considerations of the sort have stood in the way of a deeper analysis of the intellectual property regime. We contend that such an analysis must be grounded in a political economy of information approach.

To the extent that the information exceptionalism hypothesis builds on the practices of computer hacking, the experiences now made in the Rep-rap project can be called upon to question the same hypothesis. The Rep-rap project has introduced a new narrative element to the predominant critique of intellectual property. Namely, the idea that free copying can be extended to the realm of physical goods. Having said that, it is important to note that this narrative element is not merely expressed on a discursive level. Through the expenditure of their labour, the hobbyists are striving to bring their dreams to fruition. The fact that they have developed a 3D printing technology to the stage of proof-of-concept is significant for the creation of a new imaginary. When hacker-hobbyists shift their attention from proprietary software to closed hardware, the industrial economy as a whole is implicated in their critique against the intellectual property regime. In the third section of the article, we outline our own alternative critique of the intellectual property regime. It is a critique where intellectual property is put on an equal footing with private property. In both cases, the legal protections arise from the same need to safe-conduct commodity production/circulation. In the concluding section, we plot a possible scenario from our earlier reasoning. The fact that the adversaries of intellectual property are moving "away-from-keyboard" might be indicative of where the (intellectual) property regime as a whole is heading next. That is to say, some of the more controversial aspects of the current intellectual property regime, for instance, the use of digital rights management technology, will not be restrained to the realm of information goods for much longer. What the future has in store for us might be something even more sinister than anything dreamt up by Cory Doctorow: a future of "augmented property".

\section{The Anomaly of Information}

"Information wants to be free". This rallying cry of hackers and filesharers was first uttered at a hacker conference in 1984. It was Stewart Brand, a prominent figure in the American counterculture movement and a pioneer in the computer underground, who coined the phrase. Sceptics have often retorted that "information does not want anything". The refusal, however, has failed to temper the enthusiasm of the believers. To unearth the naîvité, which Stewart Brand is accused of, one must first take full measure of the truth of which he spoke. The reasoning of Stewart Brand was more advanced than is given away by the catch phrase. The full quote reads: "Information wants to be free. Information also wants to be expensive. Information wants to be free because it 
has become so cheap to distribute, copy, and recombine-too cheap to meter. It wants to be expensive because it can be immeasurably valuable to the recipient" (Brand 1987, 202).

As is seen from the quote above, no intentionality is attributed to information. Neither can Brand's reasoning be straightforwardly dismissed as a case of technological determinism. Instead, Stewart Brand counter-posed two warring tendencies and situated them in the political economy of information. His proposition sounds plausible, even prophetic. Contrary to first appearance, however, the main thrust of the argument is not that there is a tension between free and expensive in the political economy of information. Rather, the bottom line of his talk was that this contradiction is unique to the political economy of information, as opposed to political economy in general. The starting point is the familiar one about the exceptionality of information. As a non-rivalrous good, information is assumed to be radically different from tangible goods. Following Dan Schiller, we will call this idea the "information exceptionalism" hypothesis. Schiller polemicizes against the exceptional qualities attributed to information (Schiller 1997). Although we share much of his critique, we find it lacking in one respect. By denouncing the information exceptionalism hypothesis as simply a misconception, Schiller and like-minded critics fail to see how productive this idea can be to its adherers.

In our attempt to wrestle with the latter question, we will imitate the flanking manoeuvre developed in constructivist science studies. This strategy is deployed by science studies scholars to avoid getting bogged down in debates about the reality of one or another scientific fact. The limelight is instead placed on how the appearance of matter-of-factness is produced by the practitioners. Although such a line of attack seems to be beside the point, this argument can arrive at the essential by relay. When successful, the constructivist detour helps to bring out nuances, which would be lost in a reasoning, which starts with a positive assertion about how the world is. We propose to apply the same strategy to the information exceptionalism hypothesis. For the time being, we will bracket the question if the hypothesis is correct or false. Towards the end of the article we will return to this question and try to give a satisfying answer. For the time being, we will concentrate on showing how the argument about the non-rivalrous nature of information came about and acquired its current, elevated standing in most critiques against intellectual property.

Our proposition is as follows: the information exceptionalism hypothesis builds on an anomaly in a specific, scientific paradigm. We use the term "anomaly" in the strict sense given to it by Thomas Kuhn (1996). In his classic theory of science, to put it briefly, an anomaly is defined as something, which gainsays the prevailing scientific wisdom of the day. It is hard even to catch sight of the inconsistency, and impossible to resolve it within the scientific worldview of the day. Hence, an anomaly points beyond the established order, towards a new scientific paradigm which can make better sense of the observational data. However, since no way of conceptualising the world can give the ultimate and exhaustive explanation of reality, new anomalies are bound to crop up again.

The paradigm we have in mind is the economic science and its predominant traditions, large part of the classical and basically the entire neo-classical economic theory (Daoud 2011; 2010). A common denominator and key postulate of those two schools is the omnipresence of scarcity. ${ }^{1}$ Because resources are limited in relation to unbounded human needs/fancies, humans act as economic, maximising agents. It is for this reason, or so the argument goes, that economic theory can make predictions about human behaviour. It is a worldview, which must posit scarcity in order to see anything at all. To such a science, the existence of something non-rival becomes an anomaly. This phenomenon has been recognised by economists as the problem of "public goods", usually though to lead to market failures. The very act of defining public goods as a special problem does not resolve the anomaly; however, it only re-affirms the starting assumptions of the economic science. An example more closely related to the present argument is the talk about the rise of a socalled "attention economy" (Simon 1971). The abundance of information is said to have resulted in a new scarcity, i.e. the lack of attention among audiences. Hence, the market in information is superseded by a market in attention. Abundance is here defined as a scarcity of scarcity. Our point is not that non-rivalrous, abundant goods exist in the world and the economic science is flawed to the extent it fails to acknowledge them. Rather, what is important is that the anomaly is itself a product of the economist's particular way of seeing the world.

Being a product of the economic science, it follows that the problem with non-rival goods arose at the same time as this science was invented. To the founding fathers, however, it was light rather than information, which caught their puzzled attention. Henry Sidgwick observed that "the benefits of a well-placed lighthouse must be largely enjoyed by ships on which no toll could be conveniently

\footnotetext{
${ }^{1}$ Scarcity is unquestionably the dominant concept; however, there are some classical economists that include the use of abundance as for example Karl Marx or John Stuart Mill (see Daoud 2010; Xenos 1989).
} 
imposed" (Sidgwick 1901, 412). John Stuart Mill concurred that the service provided by lighthouses was best administrated collectively as a public good (Mill 1965, 968). ${ }^{2}$ A hundred years later, Ronald Coase returned to the debate over lighthouses and affirmed that it still posed a challenge to economic theory (1974). The connection between light and ideas was made by Thomas Jefferson (Peterson 1984). He famously concluded that both must be freely shared. Inventions cannot, by their very nature, be subject to exclusive private ownership. All of those statements converge in the claim that the political economy of information abides to laws different from those found in the political economy in general. This assumption was more systematically explored by the economist Fritz Machlup. He underlined the unusual properties of information:

If a public or social good is defined as one that can be used by additional persons without causing any additional cost, then knowledge is such a good of the purest type (Machlup 1984, 159).

When Stewart Brand declared that information wants to be free, he jumped on an anomaly in the economic science. His intervention was timely, since this was the decade when copyright ownership was extended to include software in most Western countries. Grievances about intellectual property law could now be addressed by turning the economic science against itself. It laid the foundation for the present, dominant critique of intellectual property in its innumerable variations. Despite the many garden varieties, the argument pivots around the discrepancy between endless digital resources and limited tangible resources. The non-existent marginal cost of reproducing knowledge is said to be in conflict with its treatment as a scarce property. It is for this reason intellectual property law is found guilty of the cardinal sin in the economic sciences: sub-optimal efficiency. Hence, the same judgement is passed on it as would befall any other obsolete industry or sector: it must perish. This conclusion is underlined by connecting back from time to time to economic theory. In the case of Yochai Benkler, this connection is even written out in the title of his book: The wealth of networks (2006). It is a beautiful rhetorical move. In a world where the economic science has shaped much official discourse and human self-understanding, a selfcontradiction within the same worldview becomes a powerful leveller for delivering critique against status quo. With the same self-assurance as economists lay down the omnipresence of scarcity and the inescapable laws of the market, critics of intellectual property assert the non-rival nature of informational resources and its exception from those same laws.

The drawback with this critique of intellectual property is that it has taken over the limited horizon of the economic science. The anomaly of non-rival (informational) goods is always-already inscribed in the logic of omnipresent scarcity. Information goods are one of a kind in relation to how the outside world is supposed to work. The indebtedness to economic theory can also be seen in the way many critics conceptualise information. It tends to be spoken of as ready-made, predefined and unchangeable units of content. In much the same way as economists are reifying the labour process, information is understood as something which can be divorced from the flow of communication and the social entanglements in which it has been made. Critics abiding to this idea tend to direct their grievances against the imposition of intellectual property claims over the potentially unlimited circulation of information. What has been violated is the economic imperative of maximising the output of (information) goods. With such an outlook, however, one will fail to understand that the problem with intellectual property starts much earlier. That is to say, it begins already with the conceptualisation of information as alienable units of content. Once information is conceived accordingly, the assignment of a content provider with intellectual property claims follows like a brief postscript. Hence, the rallying call "information wants to be free" contains the seed of its own unfreedom: commodification.

\section{Information Exceptionalism as a Boundary Object}

In what follows, we will recapitulate some of the critique against the notion of "information" advanced in the social sciences. Thereby we do not mean to suggest that the Achilles heel of the intellectual property regime consists in an erroneous definition of information, to be corrected in thought and writing alone. Indeed, we cannot even say for certain that the adversaries of intellectual property would be better off with a more nuanced and sociologically informed concept of "information". Some of the arguments below suggest the contrary. A limited, one-sided and mythical framing of "information" is attractive partly because the activists need to win over a public opinion thralled to the same mythical worldview and self-understanding. Nevertheless, we are convinced

\footnotetext{
${ }^{2}$ Similarly, some of the classical economists, for example Adam Smith (Xenos 1987), thought that under conditions of abundance, markets may even be unnecessary - indeed some neoclassical economists still believe that (e.g. Samuelson and Nordhaus 2001, 4). Some claim, as Carl Menger, that goods, which exist naturally in abundance, are per definition free goods (Menger 2004).
} 
that there are serious drawbacks with the information exceptionalism hypothesis, analytically if not politically. A closer examination of the idea of "information" is called for.

As is well known, today's dominant conceptualisation of information was laid down in Claude Shannon's seminal article A Mathematical Theory of Communication from 1948 (Shannon 1948). He sought to define information in terms of codification and transmission of messages. In other words, as signals indifferent to the meaning that they convey to the receiver. As Rafael Capurro has argued, this marked a watershed compared to how information had been understood in previous ages, going all the way back to the days of the Greeks and Romans. The concept of information used to have a broader meaning than "sending messages". It implied the act of giving form to something, such as knowledge or the human mind. This in turn implied a context dependent language and meaning creation (Capurro 2009). It is no accident that context and meaning was taken out of the equation by Shannon. Katherine Hayles has shown how his definition answered to the needs of an ascending techno-scientific industry. The industry wanted a definition that allowed reliable quantifications. Competing definitions was proposed at the time, according to which information and its content were treated as part of an inseparable whole. To assess "information as meaning", however, would require some means of measuring what had changed in the head of the recipient. It was such practical considerations, which persuaded the scientific community to side with a narrow, mathematical, and decontextualised definition of information (Hayles 1999). A whole world has since been erected around this notion of information to make it work the way it was conceived. In spite of this, the creation, transmission and operationalisation of information are always and every time situated events saturated with meaning. Although it can be relevant to distinguish between knowledge and information, as many cultural critics have done, the two are not antithetical in the sense that one carries meaning and the other does not (Malik 2005).

The setting apart of information from the material substrate in which it inevitably is inscribed should be recognised as a major cultural invention. It has given rise to, among other things, notions about "cyberspace" and "virtual reality". In the 1990s, the Internet was customarily depicted as a disembodied realm of information flows. The attractiveness of this idea can partly be explained by that it drew strength from a millennial-old dualism in philosophical thinking, sometimes spoken of as an opposition between form and matter, other times as mind and body, and so on (Hayles 1994; Fuchs 2003). In the new media studies literature, variations upon this dualism have been equally prolific. For instance, the same opposition tends to resurface when the "virtual community" is contrasted with real, geographically bounded communities (for a critique: Proulx and Latzko-Toth 2005). Among legal scholars, a parallel discussion has raged if the virtual worlds constitute a separate jurisdiction requiring unique laws (Lastowka and Hunter 2004). The picture of cyberspace as a disembodied realm of information has come under sustained scholarly critique in the last decade. Indeed, in some quarters, expelling any trace of dualistic and/or transcendental thought has become the highest cause an academic writer can aspire for. If we hesitate to go down this road, it is because the history is full of counter-examples of how the idea of a transcendental Beyond has served as a point from which the positivity of empirical existence could be opposed. Some examples from different ages include a kingdom of heaven, natural rights, or the declaration of independence of cyberspace. The now infamous declaration by Perry Barlow would have been pointless if he had thought that cyberspace was otherworldly in an absolute sense. While cyberspace allegedly was out of reach from the states of the industrial world, Barlow hoped that a wind of change would blow from this virtual Beyond and transform the old into something new and better (Barlow 1996). The lesson is the following: The moment something (information, cyberspace, etc.) is posited as separate from its surroundings, it has already spilled over that boundary and begun to affect the "outside". Indeed, was it not this spilling-over effect Barlow longed for? The same strategy is adopted by the adversaries of the current intellectual property regime when they build their argument around the information exceptionalism hypothesis.

The observation above can be further elaborated on by borrowing two popular terms from the science studies literature, boundary work and boundary objects. The first term was proposed by Thomas Gieryn. He used it to describe how science is separated from non-science by the efforts of scientists to uphold their professional status vis-à-vis amateur scientists and religious contenders. The lesson worth emphasising in the context of the present argument is that the boundary is not naturally given. It does not exist independently of the practitioners' whereabouts. On the contrary, the boundary has to be perpetually maintained, defended and re-negotiated (Gieryn 1983). The second term was introduced by Susan Leigh Star and James Griesemer. Their contribution consisted in treating the boundary not merely as a marker of difference but equally as an interface enabling communication across heterogeneous, scientific communities. The boundary object was plastic enough to adapt to local needs, while robust enough to maintain a common identity across 
different sites (Star and Griesemer 1989; Lamont and Molnár 2002). The original definition of boundary work does not match perfectly onto the information exceptionalism hypothesis outlined above, but it does a good enough job to bring home our most important point. The boundary between informational resources and physical goods is not a given. It must be upheld through continuous work. The exceptionalism of information and the separateness of the virtual realm constitute the boundary object of the campaigners for information commons. In line with Susan Leigh Star and James Griesemer's understanding of the term, the vagueness of the notion "information" is not a flaw but a strength. It is this imprecision, which allows hackers and activists of varying persuasions to communicate and collaborate with each other. This is probably even more important to hackers than to the average science community, given the sharp ideological differences, which are housed in the same subculture. This corresponds in a way with the observation about the "political agnosticism" of hackers outlined by Gabriella Coleman (Coleman 2004) There is a less innocent side to this story. As Geoffrey Bowker and Susan Leigh Star clarified in a later work, the classifications laid down by a boundary object have biases, which validate some points of view while rendering other positions invisible and/or unspeakable (Bowker and Star 1999).

In order to see what has been rendered invisible in the boundary object, which we have named "the information exceptionalism hypothesis", a quote by one of the chief architects behind the movement for creative commons licenses, Lawence Lessig, can be instructive. After having made a passionate case in favour of that information and culture should be distributed in a commons and free of charge, Lessig reassures his readers that markets and commons can coexist side-by-side. He underlines that not all resources can nor should be organized in a commons: "While some resources must be controlled, others can be provided much more freely. The difference is in the nature of the resource, and therefore in the nature of how the resource is supplied" (Lessig 2001, 94). According to this argument, it is in the nature of informational, non-rival resources to be organised in a commons. In the same vein, rival, tangible resources are thought of as suited for markets. It is the nature of the resource, which determines if a product is rival or non-rival. While intellectual property is said to create scarcity, traditional property is assumed to be grounded in objectively existing limitations in the real world. By implication, ownership of tangible, rival goods is seen as "operational", not to say "optimal". The same line of thought underpins Yochai Benkler's argument, which has been equally influential in shaping the predominant critique against the current intellectual property regime: "In the context of information, knowledge, and culture, because of the nonrivalry of information and its characteristic as input as well as output of the production process, the commons provides substantially greater security of context than it does when material resources, like parks or roadways, are at stake" (Benkler 2006, 146).

More so than Lawrence Lessig, Yochai Benkler recognises that his reasoning rests on technological and social conditions, which may change in unpredictable ways. As a consequence, the balance scales between commons and markets might shift and needs to be reassessed from time to time. However, technological and social change is understood as external factors acting upon Benkler's computation from an Outside. It is not seen as integral to a larger social conflict, in which the two law scholars are taking part, and where the demarcation line between commons and markets is the prize of the game. Hence, both writers can stipulate the possibility of finding an optimal balance point between commons and markets. It can be established in a technical, neutral manner. What keep this from happening are uninformed and/or corrupted legislators. Although Lawrence Lessig and Yochai Benker deplore this state of things, they do so without overstepping the limit for a respectable US liberal intellectual. That limit has been laid down by the hypothesis about information exceptionalism. It asserts that a critique against the current intellectual property regime does not imply a general critique of private property. It affirms that the advocacy for information commons is not at the same time an assailment against the free market.

This bias of the boundary object must be respected by everyone who wants to play ball, including those critics of the intellectual property regime who are typically identified as "leftists". For instance, Richard Stallman, the founder of the Free Software Foundation, insists on not using the word "intellectual property". He argues that this term causes confusion by gathering a range of distinct legislation under a catch-all phrase (Stallman 2006). ${ }^{3}$ This wish to separate private property from the critique of intellectual property is also suggested by the iconic catch-phrase of the Free Software Foundation: "free as in free speech, not free as in free beer". By framing the issue in this

\footnotetext{
${ }^{3}$ This argument has been taken one step further by libertarian critics of intellectual property. Instead of talking about "intellectual property", they promote the derogating term "intellectual monopoly". The case against property rights can thus be refashioned as an attack on state regulations and market distortions (Boldrin and Levine 2008). Of course, such a line of argument is underpinned by the old libertarian fallacy that private property and markets can exist independently of the state and its legal powers.
} 
way, the case for information commons can be portrayed as a defence of civil liberties, rather than being seen as an attack on private property and thus a struggle for economic redistribution. No one can deny that this way of presenting the issue has advantages. Had the Free Software Foundation not adopted a pragmatic stance, they would probably have been marginalised and become yet another "beautiful soul". Indeed, it could even be argued that the case for information commons becomes all the more efficient in criticising private property and free markets by not giving itself away as such a critique. One of us has argued in an earlier work that the ingenuity of the free software license "GPL" consists in that it abides perfectly well to an abstract, idealised free market, while making the really-existing market hard to sustain (Söderberg 2009). This threat has not escaped the attention of conservative commentators in the US. It has sparked debates about "commonism" and Marxism/Lessigism, generating much heat and no clarifying light (for a summary, see: Dan Hunter 2004). Although we appreciate the pragmatic stance of the free software advocates, the question must nonetheless be raised: can the ills of the intellectual property regime be effectively combated from an intellectual position which stops short of investigating the political economy of information? To the extent that one believes that political action must be guided by relentless, theoretical investigation, and self-reflection, the answer is "no".

\section{Political Economy of Information}

This far into the argument, it is time to close the bracket in which we initially put the question, if the information exceptionalism hypothesis is an outright false proposition. Our tentative answer is that the exceptionalism attributed to information is not incorrect, as much as it is partial and onesided in its portrayal of the world. It holds out the wrong end of the rope when we are about to start an inquiry into intellectual property and information commons. If this seems like a minor correction, hardly worth the entire stir previously made in the article, then we contend this different tilt of the research program leads to an altogether different result, both analytically and politically. When we set out to question the exceptionality of information, what we want to bring attention to is the orientation of the whole inquiry, which gives raise to this peculiar phenomenon. The crux is the notion of scarcity, the alpha and omega of the economic science which gives raise to its Other: inexhaustible abundance of informational resources.

An implicit assumption of the information exceptionalism hypothesis is a matter-of-factness assertion about the positive existence of scarcity in the physical world. This point of departure can be contrasted with a historically and sociologically informed approach, according to which scarcity (both of information and tangible goods) always is inscribed in prevailing social relations. It is the historical transformation of those social relations as a whole, which must be put under scrutiny in the first place. This claim might come across as counter-intuitive. A non-believer will not be approachable to this kind of argument without first having suspended her sense-certainty about the prevalence of scarcity in the physical world. This is a lot to ask for, because the certainty is grounded in everyday experiences of shortage and want. When she lifts herself above this immediate experience, however, scarcity can be interpreted with new eyes, now looked at from the viewpoint of society as a whole. Such a horizon is offered in the anthropological approach of Marshall Sahlins. In his study of archaic societies, he made a lucid comment about the condition of life in modern society: "The market-industrial system institutes scarcity, in a manner completely unparalleled and to a degree nowhere else approximated. Where production and distribution are arranged through the behaviour of prices, and all livelihoods depend on getting and spending, insufficiency of material means becomes the explicit, calculable starting point of all economic activity" (Sahlins 1972, 4).

A long row of historians have demonstrated how this state of affairs begun with the enclosure movement in fifteenth and sixteenth century England. Land that previously had been held in common was fenced in and assigned to individual rights holders. Crucially, with this historical perspective, the political economy of information is not treated as a one-odd-out. The current expansion of the intellectual property regime, in James Boyle's memorable words, amounts to "a second enclosure movement" (Boyle 2003). The stress is placed on historical continuity rather than discontinuity. Furthermore, the internal relation between private property and intellectual property is given due credit. Nothing said so far denies the common sense perception that there is a qualitative difference between information and tangible goods. Nor do we deny that it can be meaningful to reflect over this difference. What is in question is how to best frame such an inquiry. The point was forcefully made by Dan Schiller in his critique of the information exceptionalism hypothesis: "As against the postindustrialists' assertion that the value of information derives from its inherent attributes as a resource, we counter that its value stems uniquely from its transformation into a commodity-a 
resource socially revalued and refined through progressive historical application of wage labor and the market to its production and exchange" (Schiller 1988, 41).

The informational use value and its inherent characteristics should not be taken as the referential point for an analysis. The reason is that the informational product is not a solid, stable entity in its own right. It is but a moment in the metamorphosis of the labour process. This claim does not necessarily refute the sensation that there has been a rupture, which roughly corresponds with the spread of information technology. If there is a discontinuity, however, it should not be sought in a discrepancy between non-rival informational goods and tangible, rival goods. It is better described as a rupture in the labour process. Numerous scholars have attempted to name this rupture, some examples include: immaterial labour, social labour and scientific labour. The controversies surrounding these claims can be left aside for now. ${ }^{4}$ What is important here is that the contradictions arising from the political economy of information cannot be satisfyingly accounted for as "infinite reproducible information treated as a scarce resource". It is more appropriate to think of it as private property being straitjacketed onto a socialised labour process that flows from communication. The chief advantage with the latter description is that it enables a more dynamic analytical approach. It allows us to study given reality as transitional in its becoming. The strengths of this approach are plain to see when the object of study is perpetually transformed by technological change and creative destruction.

The line between informational and tangible goods, the virtual and physical realm, and, by implication, commons and markets, might at one point have seemed stable and self-evident. Arguably, it looks less stable the more hardware and software technologies converge. There is a lot of political clout behind bringing about such a convergence, as is suggested by numerous policy documents about an "augmented reality" and the "Internet of things". Large amounts of funding goes into making these ideas come true. A more concrete example is field-programmable circuits. It is widely used in the computer industry since more than a decade back. These circuits are manufactured in such a way that the final design can be reprogrammed at a later date. From these examples, it might sound as if we had introduced a technological deterministic assumption to make our analysis more dynamic. Not at all that the breakthrough of field-programmable circuits owed to something else than an innate trajectory of technological development can easily be verified. A testimony from an industry leader in the 1990s, anticipating the increased use of fieldprogrammable circuits, puts our point succinctly: "Our edge is that we can use easily available programming skills to do what previously required expensive and hard-to-recruit chip designers" (Gibson 1999, 38). Having said that, we do not want to imply that everything can be reduced to the urge of capital to reduce labour costs. The hobbyists building open source 3D-printers give proof of other rationales for striving towards a convergence between hardware and software. By articulating their dreams, and, crucially, through the exertion of their labour, the hobbyists are contributing to a reconfiguring of the world (virtual and real) along the same lines.

Having put this much stress on the transitory character of the given reality, and after having borrowed extensively from constructivist science studies, we need to add a word of caution. What has been said so far does not mean that the world can be reshaped effortlessly and at will. To get anywhere at all, the hobbyists in the Rep-rap community have to overcome one technical hurdle after the next, sometimes coming to a full stop when the difficulties they encounter are overpowering. This caveat is also made by constructivist science scholars. We diverge from many of them, however, in that we do not believe that all explanatory weight can be placed on locally situated practices. The latter intellectual position goes astray in its disregard for historical forms, or, with a different terminology, the inertia of path-dependency. What is thereby sacrificed is a sense of proportions and gravity (Söderberg and Netzen 2010). If we were to weight the impact of the Rep-rap community against, let's say, the reorganisation of the labour process by capital, we would find that the latter has been a magnitude more important factor for influencing technological change. Nevertheless, the example with the open source 3D printer helps to demonstrate our argument. Namely, that there can be no once-and-for-all, a priori demarcation line between informational resources and physical goods. This line is continuously created and redrawn in the labour process, broadly

\footnotetext{
${ }^{4}$ For the record, we would like our reservations against the immaterial labour thesis to be noted. Despite occasional assertions to the contrary by Michael Hardt and Antonio Negri, the thrust of their argument (as well as that of Maurizio Lazzarato) points to a definition of "immaterial labour" predicated by the products it gives rise to, i.e. informational and/or affectual goods. By implication, those products are contrasted with tangible, physical goods produced by "material labour" (Lazzarato 1996; Hardt and Negri 2005; for a critique, see: Camfield 2007). It is hard to square this reasoning with Marx's famous remark in Capital, laying down that for an analysis of commodity production: "The nature of these needs, whether they arise, for example, from the stomach, or the imagination, makes no difference" (Marx 1976, 125). It suggests that the critique which we are here developing against the information exceptional hypothesis could also be directed against the notion of "immaterial labour".
} 
understood. Hence, the information exceptionalism hypothesis, and all the arguments which rest on top of it - including the predominant critique of intellectual property - comes up short. Faith in this hypothesis is likely to persist no matter what, for all the reasons outlined above. Still, we believe that by deciding against such an analytical procedure, in favour of an intellectual approach anchored in political economy and where the stress is placed on historical continuity, one can get a better sense of the future struggles over the intellectual property regime.

\section{Conclusion - Freeing Information, Freeing Atoms}

In the present article, we have questioned the self-evident appearance of what we elect to call the information exceptionalism hypothesis. This hypothesis underpins most of the critiques against intellectual property upheld both by activists and their sympathisers in the academy. The argument is compelling because it constructs a string of statement following from something, which seemingly is self-evidently true. Namely, the claim that information is substantially different from material resources. We have argued that the self-evident appearance of this claim does not simply rest on it being an accurate description of what information "really is". Rather, it owes partly to the fact that the information exceptionalism hypothesis has been cut out of the same cloth as the economic science. Some of the matter-of-factness, which permeates the economic discipline, has thus been endowed upon this hypothesis. It is thus the critics of intellectual property are able to exploit an anomaly in the paradigm of economic science. Crucially, economics is not a science like any other, but the one which all of us have been subjected to and formed by during the past few decades of neoliberal hegemony. A key postulate of this science lays down the omnipresence of scarcity. The critics of intellectual property have discovered the radical Other of this postulate, namely: the abundance of non-rival, informational goods. Hence, the rationale for intellectual property is overthrown from within the citadel of private property. The liturgy of free markets is now being sung in praise of the information commons. The irony of this reversal is easy to appreciate, as are the tactical advantages. The price to pay, however, is that the blind spots of the economic science are duly reproduced in the critique of intellectual property. Some high-profile champions of the information commons, which we have in mind, are Lawrence Lessig and Yochai Benkler, together with their innumerable followers. There are also some shining exceptions among the legal scholars, such as James Boyle. The latter has formulated a critique of intellectual property, which incorporates the historical insights of political economy and draws parallels to the first enclosure movement. His analysis starts in a broader critique of private property and commodification as moments in a historically developed, social whole. This has not, however, been the road travelled by most critics and campaigners against intellectual property. A lot of work has instead been put into policing the borders between intellectual property and private property. A case in point is when free software advocates distinguishes between free as in "free speech" and free as in "free beer". The point being that free software is strictly about civil rights issues, while protestations over price and markets are exempted from the struggle against the intellectual property regime. We believe that this approach has exhausted itself. This claim can be illustrated with a quote from Paolo Virno, although uttered in a completely different context. Free beer has become indistinguishable from free speech, in: "the era in which language itself has been put to work, in which language itself has become wage labour (so much so that 'freedom of speech' nowadays means no more and no less than the 'abolition of wage labor')" (Virno 1996, 271).

We wish to follow the trend, which Virno hints at in the quote above but we have chosen to start from a different point of departure. It was proposed that the boundary work of hackers, activists and academics campaigning against intellectual property is being destabilised due to the introduction of a new narrative element. Namely, the exclamation that, to put it in the jargon of the Californian ideology: "atoms are the new bits". At the centre of articulating this new imaginary are the hobbyists building open source 3D printers, the Rep-rap project. Many of them are convinced that their work will result in an expanded conflict over intellectual property, soon to encompass physical objects too. In fact, the first cannonade has already been fired. In February 2011, a DMCA takedown notice was issued for printable 3D objects. The notice was sent to Thingiverse, a repository for 3D objects used by many hobbyists in the Rep-rap community. The individual designer making the complaint, Ulrich Schwanitz, protested that an object, which he had created, an impossible shape called a "penrose triangle", had been reverse-engineered and uploaded to Thingiverse. Eventually he dropped the charges and released his design in the public domain. Nevertheless, in the Rep-rap community and on the Thingiverse blog, this event was hailed as a first skirmish in the upcoming struggle over 3D designs and home printing. The expectation is that once a consumer market in 3D printers has been established, many industries will start to lobby for legal protections, just as the music and film-industries did in the late 1990s. 
Without necessarily endorsing the many claims made on the behalf of the Rep-rap project, we recognise its importance for introducing a new imaginary. This imaginary suggests that there can be no stable demarcation lines between commons (in which informational resources can circulate freely) and free markets (in which property ownership over tangible goods are duly respected), ultimately grounded in the nature of the resource in-itself. Hence, where to draw the line between the two will be decided in a test of strength between opposing forces. This is essentially a political struggle, although for most part it will be mediated through technological innovation. In fact, the opportunity has already been spotted by conservative think tanks. In a re-examination of the old debate about lighthouses and public goods, one economist has observed that light is now being replaced with radio signals as a means for assisting navigation. The latter technology is designed in such a way that rent can easily be extracted from the service. The writer rejoices: Due to technological change, there are no such things as natural public goods anymore. It is only institutional inertness, which holds back the relentless expansion and intensification of markets (Foldvary 2003). Indeed, with information technology, the granularity of private property can be made infinitely small. Examples hereof abound in the new markets, which have flourished on the Internet for some time. Infinite are the ways to parse up information and provide it on a pay-per basis. And atoms are the new bits. Herein lies the truth of the expanded conflict over intellectual property. It signals a future where goods and services in "meat-space" can be charged for with the same surgical precision, as is already the case on the Internet. From the perspective of the economist of tomorrow looking back at the present situation, it will appear as if the coarse way in which we are now being charged for our goods and services amounted to an endless long tail of market failures. The opportunity to close those failures, again and again and again, will drive the expansion of Digital Right Management systems to new areas. Intellectual property and traditional property converge into what might be called "augmented property". In the up-coming conflict over augmented property, piracy will be generalised to every corner of society. And everywhere we will hear the battle cry: atoms want to be free too!

\section{References}

Barlow, John Perry. 1996. A Declaration of Independence of Cyberspace. Accessed January 23, 2012. http://w2.eff.org/Censorship/Internet censorship bills/barlow 0296.declaration

Benkler, Yochai. 2006. The Wealth of Networks: How Social Production Transforms Markets and Freedom. New Haven Yale University Press.

Boldrin, Michele, and David K. Levine. 2008. Against Intellectual Monopoly. New York: Cambridge University Press.

Boyle, James. 2003. The Second Enclosure Movement and the Construction of the Public Domain. Law and Contemporary Problems 66 (1/2): 33-74.

Bowker, Geoffry C., and Susan Leigh Star. 1999. Sorting Things Out: Classification and its Consequences. Cambridge: MIT Press.

Bradshaw, Simon, Adrian Bowyer, and Patrick Haufe. 2010. The Intellectual Property Implications of Low-Cost 3D Printing Scripted 7 (1): 5-31.

Brand, Stewart. 1987. The Media Lab: Inventing the Future at MIT. New York: Viking.

Camfield, David. 2007. The Multitude and the Kangaroo: A Critique of Hardt and Negri's Theory of Immaterial Labour. Historical Materialism 15 (2): 21-52.

Cappuro, Rafael. 2009. Past, Present, and Future of the Concept of Information. tripleC-Cognition, Communication, Cooperation: Open Access Journal for a Global Sustainable Information Society 7 (2): 125-141. Accessed January 30 , 2012. http://triple-c.at/index.php/tripleC/article/view/113/116

Coase, Ronald H. 1974. The Lighthouse in Economics. Journal of Law and Economics 17 (October): 357-376.

Coleman, Gabriella. 2004. The Political Agnosticism of Free and Open Source Software and the Inadvertent Politics of Contrast. Anthropological Quarterly 77 (3): 507-519.

Daoud, Adel. 2011. Scarcity, Abundance, and Sufficiency: Contributions to Social and Economic Theory, Göteborg Studies in Sociology No 46. Gothenburg: University of Gothenburg. Accessed January 23, 2012. http://gupea.ub.gu.se/bitstream/2077/24686/1/gupea 2077 24686 1.pdf

Daoud, Adel. 2010. Robbins and Malthus on Scarcity, Abundance, and Sufficiency: The Missing Sociocultural Element. American Journal of Economics and Sociology 69 (4): 1206-1229.

Foldvary, Fred E. 2003. The Lighthouse as a Private-Sector Collective Good. In: The Half-Life of Policy Rationales: How New Technology Affects Old Policy Issues, edited by Fred E. Foldvary and Daniel B. Klein, 38-59. New York: New York University Press.

Fuchs, Christian. 2003. The Self-Organization of Matter. Nature, Society, and Thought 16 (3): 281-313.

Gieryn, Thomas F. 1983. Boundary-Work and the Demarcation of Science from Non-Science: Strains and Interests in Professional Ideologies of Scientists. American Sociological Review 48 (6): 781-795.

Gibson, M. 1999. Can Software Replace Hardware. Ericsson Connexion, June.

Star, Susan Leigh, and James R. Griesemer. 1989. Institutional Ecology, 'Translations' and Boundary Objects: Amateurs and Professionals in Berkeley's Museum of Vertebrate Zoology, 1907-39. Social Studies of Science 19 (3): 387-420.

Hardt, Michael, and Antonio Negri. 2005. Multitude: War and Democracy in the Age of Empire. London: Hamish Hamilton.

Hayles, Katherine. 1994. Boundary Disputes: Homeostasis, Reflexivity, and the Foundations of Cybernetics. Configurations 2 (3): 441-467. 
Hayles, Katherine. 1999. The Condition of Virtuality. In The Digital Dialectic: New Essays on New Media, edited by Peter Lunenfeld, 68-95. Camebridge: MIT Press.

Hunter, Dan. 2004. Marxist-Lessigism. Legal Affairs: The Magazine of the Intersection of Law and Life, November/December.

Kopytoff, Igor. 1986. The Cultural Biography of Things: Commoditization as Process. In The Social Life of Things: Commodities in Cultural Perspective, edited by Arjun Appadurai, 64-91. Cambridge: Cambridge University Press.

Kuhn, Thomas S. 1996. The Structure of Scientific Revolutions. Chicago: University of Chicago Press.

Lamont, Michèle, and Virág Molnár. 2002. The Study of Boundaries in the Social Sciences. Annual Review of Sociology 28: 63-90.

Lastowka, Greg, and Dan Hunter. 2004. The Laws of the Virtual Worlds. California Law Review 92 (1): 3-73.

Lazzarato, Maurizio. 1996. Immaterial Labour. In Radical Thought in Italy: A Potential Politics, edited by Paolo Virno and Michael Hardt, 133-147. Minneapolis: University of Minnesota Press.

Lessig, Lawrence. 2001. The Future of Ideas: The Fate of the Commons in a Connected World. New York: Random House.

Machlup, Fritz. 1984. Knowledge: Its Creation, Distribution and Economic Significance. Princeton: Princeton University Press.

Malik, Suhail. 2005. Information and Knowledge. Theory, Culture \& Society 22 (1): 29-49.

Mansell, Robin. 2004. Political Economy, Power and New Media. New Media \& Society 6 (1): 96-105.

Marx, Karl. 1976. Capital: A Critique of Political Economy: Volume 1. London: Penguin Books.

Menger, Carl. 2004/1871. Principles of Economics. Grove City: Libertarian Press, Ludwig von Mises Institute.

Mill, John Stuart. 1965. Principles of Political Economy. In The Collected Works of John Stuart Mill, Vol. III, edited by John M. Robson. London: Routledge.

Mosco, Vincent. 1996. The Political Economy of Communication. London: Sage Publications

Peterson, Merrill D., ed. 1984. Writings/Thomas Jefferson. New York: Literary Classics of the US.

Proulx, Serge, and Guillaume Latzko-Toth. 2005, Mapping the Virtual in Social Sciences: On the Category of "Virtual Community". The Journal of Community Informatics 2 (1): 42-52.

Sahlins, Marshall David. 1972. Stone Age Economics. Chicago: Aldine Publishing Company.

Samuelson, Paul. A., and William. D. Nordhaus. 2001. Economics. Boston: McGraw-Hill.

Schiller, Dan. 1988. How to Think About Information. In The Political Economy of Information, edited by Vincent Mosco and Janet Wasko, 27-43. Madison: University of Wisconsin Press.

Schiller, Dan. 1997. The Information Commodity: A Preliminary View. In: Cutting Edge: Technology, Information Capitalism and Social Revolution, edited by Jim Davis, Thomas A. Hirschl, and Michael Stack, 103-120. London: Verso.

Shannon, Claude E. 1948. A Mathematical Theory of Communication. The Bell System Technical Journal 27: 379-423, 623656.

Sidgwick, Henry. 1901. The Principles of Political Economy. London: Macmillan.

Simon, Herbert A. 1971. Designing Organizations for an Information-Rich World. In Computers, Communication, and the Public Interest, edited by Martin Greenberger, 37-72. Baltimore: The Johns Hopkins Press.

Stallman, Richard. 2006. Did You Say “Intellectual Property"? It's a Seductive Mirage. Policy Futures in Education 4 (4): 334-336.

Söderberg, Johan. 2009. Hackers GNUnited. In: Free Beer, edited by Stian R. Eide, 89-106. Göteborg: Lulu.

Söderberg, Johan, and Adam Netzén. 2010. When All That Is Theory Melts Into (Hot) Air: Contrasts and Parallels Between Actor Network Theory, Autonomist Marxism, and Open Marxism. Ephemera 10 (2): 95-118.

Terranova, Tiziana. 2000. Free Labour. Producing Culture for the Digital Economy. Social Text 18 (2): 33-57.

Virno, Paolo. 1996. Notes on the General Intellect. In Marxism Beyond Marxism, edited by Saree Makdisi, Cesare Casarino, and Rebecca E. Karl, 265-272. London: Routledge.

Xenos, Nicholas. 1989. Scarcity and Modernity. London: Routledge.

\section{About the Authors}

Johan Söderberg

holds a PhD in Science and Technology Studies from University of Göteborg, Sweden. One of the central questions in his research concerns what kind of political subjects is emerging from conflicts surrounding new technology. His empirical material draws from free software and open hardware development, as well as related, technology-oriented social movements. This places him in the intersection between Science and Technology Studies (STS), social movement research, and innovation studies. Theoretically, he draws on critical theory, labour process theory, and cognitive approaches within social movement theory. This focus on epistemological questions seems particularly relevant in a setting where politics to a large extent is mediated through technology and technical expertise.

Adel Daoud

holds a PhD in Sociology at University of Göteborg, Sweden. His research is in economic sociology. In his thesis he studied the concept of scarcity, abundance and sufficiency in economics and sociology. One of the main interests is to bring these disciplines closer together through the development of these concepts. This includes both theoretical studies (classical texts by Carl Menger, Lionel Robbins, Emile Durkheim as well as modern schools such as ecological economics) in addition to empirical investigations (consumerism, famines etc.). Another research interest, in proximity to this general program, includes the philosophy of science. 